\title{
Socialismo libertário, educação e autodidatismo: entrevista-depoimento de Jaime Cubero
}

\author{
Antonio José Romera Valverde \\ Professor do Departamento de Filosofia da PUC-SP e do Departamento de Fundamentos Sociais e Jurídicos da Administração \\ da FGV, São Paulo. E-maill: valverde@pucsp.br ou antonio.valverde@fgv.br
}

\section{Resumo}

A entrevista-depoimento de Jaime Cubero (1927-1998), figura ímpar dos meios anarquistas paulistanos, é precedida de considerações sobre socialismo libertário, educação e autodidatismo, demarcadas pela contraposição de aspectos da luta social no Brasil desde meados do século XIX e em parte do século XX. As considerações iniciais cumprem o papel de apresentação dos entornos da entrevista-depoimento, cedida no Centro de Cultura Social, no bairro do Brás, na cidade de São Paulo, entre os dias 5 e 9 de maio de 1989.

Poucos movimentos sociais e doutrinas político-filosóficas são tão desconhecidos como o socialista libertário ${ }^{1}$ ou anarquista. Mesmo intelectuais e o público medianamente informado se utilizam de lugares-comuns para identificá-los. Tratam-no, fragmentariamente, como individualismo radical, negação do Estado, da sociedade burguesa, dos sistemas religiosos ou, ainda, por liberalismo carbonário, violência, desordem, utopia... Poucos concebem o que pode vir a ser mutualismo, federalismo, anarco-sindicalismo, comunismo libertário e uma sociedade pensada desde as necessidades verdadeiras e não da produção caótica. Uma sociedade em que a noção de progresso fosse outra que não a existente. Poucos também conhecem a concepção libertária de homem fundada na razão, no trabalho e na solidariedade. Menor, porém, deve ser o número daqueles que reconhecem o papel da educação "científica e racional", integral e libertadora, para as classes trabalhadoras de todo mundo.

Dentre outras tantas possibilidades de caracterização do socialismo libertário, os excertos retirados de obra de Kropotkin (s/d) favorecem a elucidação do movimento em pauta:

[...] o anarquismo não procede de uma determinada descoberta científica nem assen- ta-se em um sistema definido de filosofia. [...] Como socialismo, e em geral todos os movimentos de caráter social, o anarquismo originou-se do povo e só conservará a vitalidade e a força criadora que the são inerentes enquanto se mantiver com a sua peculiaridade de movimento popular. [...] Embora o anarquismo, como todos os movimentos revolucionários, surgisse dentre 0 povo, do tumulto das lutas em prol das reivindicações sociais, e não de um estudo científico ou do tranqüilo gabinete do sábio, é importante, todavia, determinar o lugar que ocupa, entre as diversas correntes do pensamento científico e filosófico moderno. (p. 1-17)

Kropotkin sustenta ainda que os socialistas libertários

[...] concebem a sociedade como uma vasta rede de associações de toda a espécie em que as relações mútuas dos membros que

1. A expressão "socialismo libertário" foi inventada por Sébastian Faure no ato da fundação de La Revue Blanche, órgão anarquista, na França. Segundo este, naquele Estado, encontrava-se proibida a propaganda anarquista (sic). No desenvolvimento do texto em pauta, o termo "anarquismo" e a expressão "socialismo libertário" são tomados pela sinonímia e pela equivalência semântica. 
as compõem são reguladas, não por leis, herança de um passado de opressão e barbárie; não por autoridades, quer estas sejam levadas ao poder por eleição, quer por herança de seus antepassados, mas organizadas mediante convênios ou acordos entre as partes componentes, livremente aceitas e a todo o tempo revogáveis, garantidos por hábitos e costumes sociais que longe de se petrificarem pela lei, pela rotina ou pela superstição, incessantemente evoluem e continuamente se ajustam às novas necessidades de uma vida livre, pelo progresso das ciências, das invenções e do constante engrandecimento dos mais elevados ideais humanos. [...] Liberdade de ação ao indivíduo para o integral desenvolvimento de todas as suas capacidades naturais de modo a assegurar de fato a sua plena individualização, isto é, do que nele possa haver de pessoal, de original. Por outros termos: nada de coação, nada de que resulte uma imposição ao indivíduo sob a ameaça do temor ou do castigo, qualquer que seja a forma adotada, ou de punição sobrenatural ou mística; a sociedade nada solicitará do indivíduo que este não haja livremente consentido; portanto, igualdade absoluta de direitos de todos. (p. 89-90)

No Brasil, o (quase) desconhecimento do socialismo libertário pode ser explicado, em parte, pela perda da hegemonia dos militantes anarquistas do comando das lutas sociais, em meados dos anos 1920, com a criação do Partido Comunista ${ }^{2}$. Contudo, o novo aglutinante das lutas sociais herdou um ativo de greves, centros culturais, escolas racionalistas, publicações jornalísticas e livrescas, bibliotecas, montagens teatrais, meetings, conjugados com o forte espírito de combate e de esperança dos militantes anarquistas, nada desprezível.

Deve-se acrescentar que a perda da hegemonia político-social é tributária, também, do desfalque nos quadros da militância libertária mais ativa, promovido pela repressão policial por meio do degredo tanto para fora do país como internamente. 0 caso mais chocante e extremo é o da criação da cidade de Clevelândia ${ }^{3}$, no interior do estado do Amazonas, pelo presidente em exercício, Arthur Bernardes ${ }^{4}$. A finalidade daquela cidade - meio-fantasma, meio-ficção era abrigar os "desordeiros sociais" e forçá-los a contrair malária, à época, sem cura.

A par disso, o desconhecimento da teoria e da prática socialistas libertárias explica-se pela dificuldade de acesso às obras essenciais de pensadores desse movimento, mesmo com tentativas esporádicas de atualização bibliográfica. Também não é possível pelas fontes primárias, tais como periódicos e folhetos, que raras vezes são conservados em bibliotecas e arquivos oficiais. Acrescente-se, a estes obstáculos, o fato de quase inexistirem memórias escritas de militantes anarquistas. Nem mesmo o jornalista e ativista Edgard Leuenroth, cujo nome é legenda dentro do movimento anarquista brasileiro, deixou registrada sua autobi-

2. Conferir "A formação do PCB". In: PEREIRA, A. Ensaios históricos e políticos. São Paulo: Alfa-Omega, 1979, p. 41/161.

3. "0 depoimento de um antigo ministro da Agricultura, Miguel du Pin e Almeida, sobre a repressão durante o governo Artur Bernardes (199226), permite reconstituir essa continuidade velada: 'Desde o começo da República que sempre se entendeu que as deportações, em caso de estado de sítio, deviam ser feitas do Sul para as zonas de fronteira nos estados do Pará e Amazonas, talvez em virtude do princípio constitucional que atribui à União jurisdição sobre aqueles trechos do território nacional.' [...] Este arbítrio do Estado pode ser constatado de forma viva e alargada durante 0 governo Artur Bernardes, quando se tornou tão notório como naquele período de desterro de cidadãos envolvidos nas revoltas tenentistas, militantes, trabalhadores e desempregados. 0 envio para Clevelândia, apesar das alegações do antigo ministro que examinamos, representava alguma coisa equivalente a uma sentença de morte. Um relatório encaminhado na época ao ministro da Agricultura, 'Viagem ao Núcleo Colonial Cleveland', mostra que, em 1926, dos 946 prisioneiros desterrados para Clevelândia, depois da revolta de 1924, 444 haviam morrido. [...] Alguns [militantes operários] foram expulsos do Brasil, outros enviados ao presídio na ilha Rasa e maioria foi mandada para o campo de internamento em Clevelândia, como os redatores de A Plebe de São Paulo". PINHEIRO, P. S. Estratégias da ilusão: a Revolução Mundial e o Brasil, 1922-1935. 2. ed. São Paulo: Cia. das Letras, 1991, p. 87-88-109.

4. À guisa de ilustração da justiça poética, eis o poema 0 lluminado, em homenagem a Artur Bernardes:

"Os inimigos diziam: / - Ninguém até hoje viu, / Ninguém não viu esse homem. / Além disto ele é malvado, / É rancoroso, tirano / Joga gente pela janela; / No palácio do governo / Tem 'squemas de suplícios, / Tem alçapões complicados. / Mata homem que nem formiga. / Mandou para a Clevelândia / Seiscentos bons cidadãos / Num navio envenenado. / Este homem não é homem, / É um punhal de pince-nez". MENDES, M. História do Brasil (1932). Rio de Janeiro: Nova Fronteira, 1991, p. 77. 
ografia de lutas, a despeito do que fez Anselmo Lorenzo, catalão e autodidata, em El proletariado militante ${ }^{5}$, documento histórico seminal.

No campo da Educação Libertária, o fenômeno agrava-se. Somente em meados da década de 1970, começou-se a estudar e a discutir, sistematicamente, a estratégia do desterro ${ }^{6}$ dos imigrantes europeus, que aqui aportaram ao final do século XIX e início do século passado, trazendo na bagagem a experiência de lutas sociais em ambientes urbanos e fabris. A estratégia incluía um projeto educacional como forma não só de ampliar os horizontes intelectuais e políticos, mas assegurar os rumos da militância proletária de modo autônomo, e propor, também, como fim último, quiçá inalcançável, a possibilidade da construção de uma "autêntica" cultura popular.

Foram aqueles imigrantes que inauguraram, como demiurgos e "novos bárbaros", sistematicamente, a luta social no Brasil. Eles trouxeram o anarquismo e, por meio dessa concepção política da ordem social, encaminharam o processo da incipiente emancipação do proletariado brasileiro.

Oficialmente, o anarquismo já tinha aportado no país por um decreto de Dom Pedro 11. Mecenas das artes, cioso de novidades, tentado a modernizar o Brasil pelo alto e mostrar um perfil civilizado da nação brasileira no exterior, tomou conhecimento, em uma de suas estadas na Itália, de um libreto intitulado $\mathrm{La}$ tèrra libera. Admirado com a utopia positiva de recriação da ordem social em outras bases, concedeu um pedaço de terra, ao sul do Paraná, para que os idealizadores daquelas idéias realizassem seus sonhos. E a história da Colônia Cecília ${ }^{7}$ é medianamente conhecida...

A exposição do ideário socialista libertário de educação permite a compreensão de aspectos da prática proletária nele contido e expresso. Prática de ruptura/prática de integração na sociedade capitalista: essa oscilação pendular dá a medida do espectro das propostas operárias historicamente dadas. E o parentesco mais próximo dessa forma de reflexão encontra, certamente, parâmetro na dialética do senhor e do escravo, de matriz hegeliana, pois o processo de trabalho cria autoconsciência não somente no trabalhador - cujo ser é o trabalho -, mas também no senhor, de modo a suplantar a reificação das relações entre os homens, sob o capitalismo, como relações entre coisas que, em verdade, são relações entre homens e forças históricas.

Compreender o corpus pedagógico proposto pelos socialistas libertários, em suas realizações práticas e formulações teóricas no Brasil, implica situá-la não só no interior do movimento operário, mas, sobretudo, situá-la em relação à estrutura social capitalista em desenvolvimento tardio no Brasil, o que significa localizá-la no processo de formação e reprodução da classe proletária que pudesse efetivar esse desenvolvimento.

A constituição e a generalização do modo de produção capitalista, ao menos "classicamente”, é sinônimo da constituição e generalização das classes sociais que compõem a relação fundamental desse modo de produção: capitalista e proletária. E “o capital não é dinheiro, nem ações, nem quaisquer outros títulos de propriedade, nem instalações ou máquinas. Nada disso é capital; quando muito, são símbolos ou expressões do capital" ${ }^{8}$. 0 capital é uma relação social, uma relação histórica de produção social.

Como escreveu Marx num manuscrito conexo a Trabalho assalariado e capital, datado de 1849, intitulado "0 salário", "o verdadeiro significado da educação, para os economistas filantropos, é a formação de cada operário no maior número possível de atividades indus-

5. LORENZO, A. El proletariado militante. Madrid: Alianza, 1974.

6. A expressão "estratégia do desterro" significa a forma cultural de adaptação do imigrante europeu às condições reinantes no Brasil ao final do século XIX e princípio do século XX. Estratégia entendida no sentido amplo de criação e de defesa da cultura operária. Sobre esse tema conferir "A estratégia do desterro". In: HARDMAN, F. F. Nem pátria, nem patrão! (Vida operária e cultura anarquista no Brasil). 2 ed. São Paulo: Brasiliense, 1984, p. 59-110.

7. A propósito, conferir: SCHMIDT, A. Colônia Cecilia: uma aventura anarquista na América - 1889 a 1893. São Paulo: Anchieta, 1942; SOUZA, N S. de. 0 anarquismo da Colônia Cecília. Rio de Janeiro: 1970; e MELLO NETO, C. de. 0 anarquismo experimental de Giovanni Rossi: de Poggio al Maré à Colônia Cecília. Ponta Grossa: UEPG, 1998.

8. BERNARDO, J. Capital, sindicatos, gestores. São Paulo: Vértice, 1987, p. 52. 
triais possiveis, de tal forma que, se é afastado de um ramo pelo emprego de uma nova máquina ou por uma mudança na divisão do trabalho, possa instalar-se noutro lado o mais facilmente possível" 9 . Porquanto, "a miséria não ensina apenas o homem a orar, mas ainda muito mais: a pensar e a agir" ${ }^{10}$, frente às vicissitudes do capital em relação ao trabalho.

0 autodidatismo tem sido um tema caro aos filósofos das Luzes e filho dileto da teoria educacional libertária, em parte, porque a maioria dos militantes anarquistas foram autodidatas, num tempo em que o militante carecia de compreender as contradições da ordem capitalista e, para além delas, encaminhar ações políticas reivindicatórias. 0 mais destacado autodidata com altura intelectual inconteste foi Joseph Proudhon (1809-1865), cuja obra e ação política inspiraram movimentos sociais relevantes, como o sindicalismo, o mutualismo e o pacifismo. Experiências pedagógicas do autodidatismo, obra do professor francês Joseph Jacotot, foram estudadas por Rancière em Le maître ignorant: cinq leçons sur l'émancipacion intellectuelle ${ }^{11}$. Jacotot ensinara francês a alunos belgas, sendo que ele mesmo desconhecia o flamengo. 0 fenômeno do autodidatismo de quadros de militantes anarquistas brasileiros, por meio sobretudo da prática do ensino mútuo, é fato atrelado aos Centros de Cultura, as verdadeiras universidades, como lócus de encontros políticos, leituras, discussões teóricas e práticas.

Para o autodidata libertário não interessa somente a aquisição dos "mecanismos" de leitura, mas, para além do domínio das conexões das letras, palavras, números, juízos, são as reflexões e as análises críticas da realidade imediata e mediata que são almejadas. Porque o autodidata anarquista opera o auto-aprendizado em vista de um horizonte político e ético de negação da ordem dada, construído desde a reflexão cotidiana acerca do trabalho, das lutas sociais, e de bem com o progresso geral da humanidade.

Contudo, como escreveu Hardman: "a consciência de classe do proletariado não deve ser buscada numa abstrata e ideológica opera- ção de separar a ciência e a ideologia, mas concreta e materialmente, ela pode ser apreendida no exame das instituições criadas pela classe (uniões, ligas, sindicatos, jornais, partidos etc.) e nas relações mantidas por essas diferentes instituições com as classes dominantes, os setores sociais intermediários e o Estado. Isto é, a formação e o desenvolvimento das formas assumidas pelo coletivo da classe operária realizam-se no interior do processo de luta de classes"12. Tais considerações encontram sustentação no conceito de classe social elaborado por E. P. Thompson ${ }^{13}$, pensado como categoria histórica, inseparável da luta de classes. Sob essa concepção, a classe não teria existência anterior aos conflitos sociais. E se tomada fora do contexto histórico dos embates sociopolíticos reivindicatórios, as classes sociais não têm realidade própria. 0 conceito de classe social estará referenciado às experiências cotidianas de seus componentes, à vida, às relações sociais, políticas, culturais e econômicas.

Para o caso brasileiro, verificou-se o surgimento de uma classe operária, "sem vínculos diretos com uma 'cultura nacional', mas ao contrário, sendo uma combinação internacional de tradições culturais européias diversas, trazidas com os imigrantes, com a experiência... advinda do trabalho camponês, do passado escravista e do pequeno setor artesanal das cidades"14, o que tem dado a especificidade histórico-social ao caso pátrio. E o movimento operário sob inspiração socialista libertária constituiu a expressão mais radical da luta social no começo do século passado. Vigoroso em seu início, minoritário nas décadas de 1930 e 1940, o que parece ser a expressão das remodelações e racionalizações na

9. Citação extraída de DANGEVILLE, R. Crítica da educação e do ensino: Karl Marx e Friedrich Engels. Trad. Ana Maria Rabaça. Lisboa: Moraes, 1978, p. 74.

10. Idem, p. 69.

11. RANCIÉRE, J. Le maître ignorant: cinq leçons sur l'émancipacion intellectuelle. Paris: Fayard, 1987.

12. HARDMAN, F. F. Op. cit., p. 29.

13. Ver ARRUDA, J. J. de A. "Experiência de Classe e Experimento Historiográfico em E. P. Thompson". In: Projeto História. N. 12. Revista do Programa de Estudos Pós-Graduados em História e do Departamento de História da PUC-SP. São Paulo: Educ, 1995, p. 97-101. 
organização da produção, introduzidas a partir de 1930, com seus conseqüentes efeitos sobre o movimento operário.

Se no momento histórico atual constatase a diluição dos valores autenticamente proletários, assimilados pelos departamentos de recursos humanos das organizações, de par com o sumiço dos horizontes de negação da ordem capitalista em curso, a causa é o sujeito histórico tradicional, o proletariado, a antítese e a negação explícita do modo de produção capitalista. Com o emperramento da luta de classes desde o final da Segunda Guerra Mundial, o sujeito encontra-se praticamente alijado do processo político-social.

Mesmo com todas as vicissitudes e a violência da história brasileira, neste e noutros séculos, os anarquistas, sempre extremamente associativos, jamais deixaram de lado sua militância, divulgando e espalhando as suas idéias por meio de jornais, campanhas públicas, palestras ou peças teatrais - às vezes com a própria vida. Exemplo vivo disso é o Centro de Cultura Social, no Brás, no município de São Paulo, que resiste incólume até os dias atuais, como sucedâneo de outros tantos existentes anteriormente. 0 registro da existência do primeiro deles, chamado de Circolo Educativo Libertário Germinal, está assentado no jornal libertário 0 Amigo do Povo, datado de 1902. Já o Centro de Cultura Social foi fundado a 14 de janeiro de 1933, num momento de refluxo do movimento operário, ao menos na vertente libertária e fechado, pela primeira vez, logo após o golpe getulista do Estado Novo, em 1937. Reaberto a 02 de junho de 1945, só voltou a cerrar suas portas em maio de 1969, em conseqüência do Ato Institucional número 5. De novo, reabriu aos 14 de abril de 1985 e segue funcionando plenamente, com palestras e difusão de obras específicas do movimento libertário. Além de agenciar discussões sobre a universidade livre, guerra e armamentos sofisticados, feminismo, autodidatismo, filosofia geral, ecologia. Manteve o mesmo estatuto desde sua fundação até maio de 2007, alterando-o por imposição da recente legislação em curso.

$\mathrm{Na}$ entrevista-depoimento de Jaime Cubero, subjazem reflexões acerca da teoria do socialismo libertário, da proposta educacional e do autodidatismo, engendradas desde o final do século XVIII, a principiar com William Godwin (17561836), considerado o precursor do anarquismo de matiz filosófico, até a síntese do autodidata catalão Francisco Ferrer y Guardia (1849-1909) ${ }^{15}$, a par de considerações pontuais sobre o Centro de Cultura Social da cidade de São Paulo.

15. Conferir TRAGTENBERG, Maurício. "Francisco Ferrer e a Pedagogia Libertária”. In Educação \& Sociedade. Revista Quadrimestral de Ciências da Educação. FE-Unicamp. N. 1. São Paulo: Cortez \& Moraes, setembro 1978, p. 17/49. 